\title{
Development of O\&M Information Management Framework using Configuration Management for Gas Pipeline Project in Permafrost Areas
}

\author{
Seo-Kyung Won ${ }^{1}$, Choong-Hee Han $^{2}$ and Junbok Lee ${ }^{3}$ \\ ${ }^{1} \mathrm{Ph} . D$. Research Professor, Dept. of Architectural Engineering, Kyung Hee University, Republic of Korea \\ ${ }^{2,3} \mathrm{Ph} . D$. Professor, Dept. of Architectural Engineering, Kyung Hee University, Republic of Korea
}

\begin{abstract}
South Korea imports $97 \%$ of its domestic energy consumption. To resolve this problem, South Korea has been striving to secure stable import sources amid the recent global crisis and competition to secure energy. As part of such efforts, Korea has concluded an agreement on procurement of natural gas from Russia for 30 years beginning from 2015. However, there are many technical issues to be solved before importing natural gas through the pipelines of the permafrost areas. This dissertation, which is part of the research on the development of the $O \& M$ information management framework for gas pipelines, aims to investigate and analyze the methodology using the IT solution of configuration management. In this study, requirements for the construction of the information management system using CM are established and the information management system will be developed in a follow-up study.
\end{abstract}

Keywords: Pipeline, Configuration Management, Information Management, O\&M, Permafrost Area

\section{Introduction}

\subsection{Background and Purpose}

South Korea imports over $97 \%$ of its domestic energy consumption. To resolve this problem, South Korea needs to secure stable energy sources. Recently, South Korea has concluded an agreement on procurement of 7.5-million-ton natural gas from Russia for 30 years beginning from 2015, under the condition of intensive cooperation for the development of oilfields and gas fields in Russia (2011 G-20 Cannes Summit). As a result, South Korea became able to participate in the development of the permafrost areas. The permafrost areas, including permanently frozen earth, are estimated to possess $22 \%$ of the world's undiscovered petroleum and gas reserves (USGS; United States Geological Survey, 2008). A considerable number of nations including the US, Germany, France, and Japan are already trying to secure energy by directly participating in resource development in permafrost areas. Since a huge amount of information is generated at each stage of a large-scale project such as the gas pipeline project, it is important to manage information. South Korea, however, does not have experience in any relevant project for resource transfer from the permafrost areas. In other words, South Korea has insufficient survey data and research materials about information, knowledge, and data management at the project planning, design, and construction stages. This dissertation, which is part of the research on the development of the O\&M information management framework for gas pipelines, aims to investigate and analyze the methodology using the IT solution of configuration management. The results of this study will be used as preliminary data for the establishment of the design-construction data management system.

\subsection{Research Scope and Method}

This study is in regards to the gas pipeline project for resource transfer from the permafrost areas. The scope of the study was limited in establishing a way to apply the configuration management technique for developing an efficient design-construction data management system.

The order of the study is as follows. 
First, the characteristics and requirements for projects to be conducted under extremely cold conditions ($40^{\circ} \mathrm{C}$ to $+20^{\circ} \mathrm{C}$ ), which cannot be found in Korea, are surveyed.

Second, data management information of the gas pipeline project is collected through a literature survey.

Third, a way to apply configuration management techniques for developing an information management system is found and suggested for utilization of information of the construction stage at the maintenance stage.

Lastly, a strategy to develop the data management system is established and a follow-up study plan is proposed.

\section{Preliminary Studies}

\subsection{Literature Survey}

Starting with studies on the design/construction techniques for the permafrost areas in the early 1990s, Korea has been conducting various studies on economic feasibility, pipe design, maintenance, pipeline welding, and dynamic behavior. However, there is an overall lack of research that has been conducted so far on information management of long-distance pipelines that consider the characteristics of the permafrost areas. Fortunately, studies on the gas pipeline project in the permafrost areas are being proactively conducted as the five-year government-led R\&D project has begun in 2014. This dissertation is also written as part of the project results.

\subsection{Permafrost Area}

The permafrost areas account for about $14 \%$ of the total land mass of the world, including the Antarctic and Arctic regions. The permanently frozen earth with the total area of 2,100 km2 accounting for $22.5 \%$ of the total land mass is widely distributed in Siberia, Alaska, Northern Canada, and Northern China. Many countries are proactively entering the permafrost areas and participating in relevant development activities with a great deal of interest. However, South Korea has very little experience in development and has poor technological capabilities, compared to other nations possessing permafrost areas. Generally, pipelines of the permafrost areas should be able to tolerate temperatures between $-40^{\circ} \mathrm{C}$ and $20^{\circ} \mathrm{C}$. In addition, the length of pipelines is over $4,000 \mathrm{~km}$. For this study, the project is assumed to be conducted for constructing 2,000-kilometer-long pipelines.

\subsection{Configuration Management}

Configuration management is a systematic approach to identify, document, and modify the characteristics of project structures, systems, and components (SSC), maintaining consistency between design requirement, facility configuration information, and physical configuration. In the 1960s, the United States Department of Defense introduced configuration management in order to advance in a competition involving missile launch capability by improving lack of uniformity and realizing accurate change management. As configuration management was gradually extended to general commercial product condition and lifespan management in the 1990s, based on the preexisting concept of the US Department of Defense, its concept has become apparent. Configuration management, an important functional field in systems engineering, has been applied for various fields including business management, quality management, technology management, and procurement management.

\section{Configuration Management Application Plan}

\subsection{O\&M Data Breakdown Structure (DBS) of Gas Pipeline Project}

The project lifecycle is generally divided into engineering/design, procurement, construction \& commissioning, and O\&M. This study was conducted to establish an O\&M stage-centric data and information management framework. Therefore, the DBS of the O\&M stage was made first. The standard EPC DBS is as shown below. 
TABLE I: Standard data breakdown structure (DBS) of the O\&M stage

\begin{tabular}{|c|c|c|c|}
\hline L.1 & L.2 & L.3 & L.4 \\
\hline \multirow{16}{*}{$\begin{array}{l}\text { 1. Pipeline } \\
\text { O\&M }\end{array}$} & $\begin{array}{l}\text { 1.1 Operation \& Maintenance } \\
\text { Planning }\end{array}$ & 1.1.1 Preparation & 1.1.1.1 Operation \& Maintenance Scheduling \\
\hline & \multirow{9}{*}{$\begin{array}{l}\text { 1.2 Transmission Pipeline Operation } \\
\& \text { Maintenance }\end{array}$} & \multirow{6}{*}{$\begin{array}{l}\text { 1.2.1 Above ground } \\
\text { Facility }\end{array}$} & 1.2.1.1 Gas Treatment Plant \\
\hline & & & 1.2.1.2 Compressor Stations \\
\hline & & & 1.2.1.3 Gas Refrigeration Stations \\
\hline & & & 1.2.1.4 Gas Distribution Stations \\
\hline & & & 1.2.1.5 Meter Stations \\
\hline & & & $\begin{array}{l}\text { 1.2.1.6 Valves, \& Pig Launcher/Receiver } \\
\text { Facilities }\end{array}$ \\
\hline & & \multirow{4}{*}{$\begin{array}{l}\text { 1.2.2 System \& } \\
\text { Infrastructure }\end{array}$} & 1.2.2.1 Corrosion Protection \& Detection Systems \\
\hline & & & 1.2.2.2 Telecommunications Towers \\
\hline & & & 1.2.2.3 Access Road \\
\hline & & & 1.3.1.1 Integrated Public Awareness Program \\
\hline & 1.3 ROW Monitoring \& Maintenance & 1.3.1 Right-of-Way & 1.3.1.2 Pipeline Patrol and Leak Detection \\
\hline & & & 1.3.1.3 Right-of-Way Maintenance \\
\hline & 1.4 Pipeline Integrity Management & \multirow[t]{3}{*}{$\begin{array}{l}\text { 1.4.1 Typical/Special } \\
\text { Pipeline }\end{array}$} & \multirow[t]{3}{*}{ 1.4.1.1 Pipeline Integrity Management Program } \\
\hline & 1.5 Emergency Response & & \\
\hline & $\begin{array}{l}\text { 1.6 Future Plans and Abandonment } \\
\text { 1.7 Others }\end{array}$ & & \\
\hline
\end{tabular}

\subsection{Interface with Information between EPC and O\&M Phase}

In this study, work is generally categorized into EPC, same as a plant project, and then named in order to understand information and data generated during the EPC phase of the gas pipeline project. The Conceptual Interface with Information is as shown below.

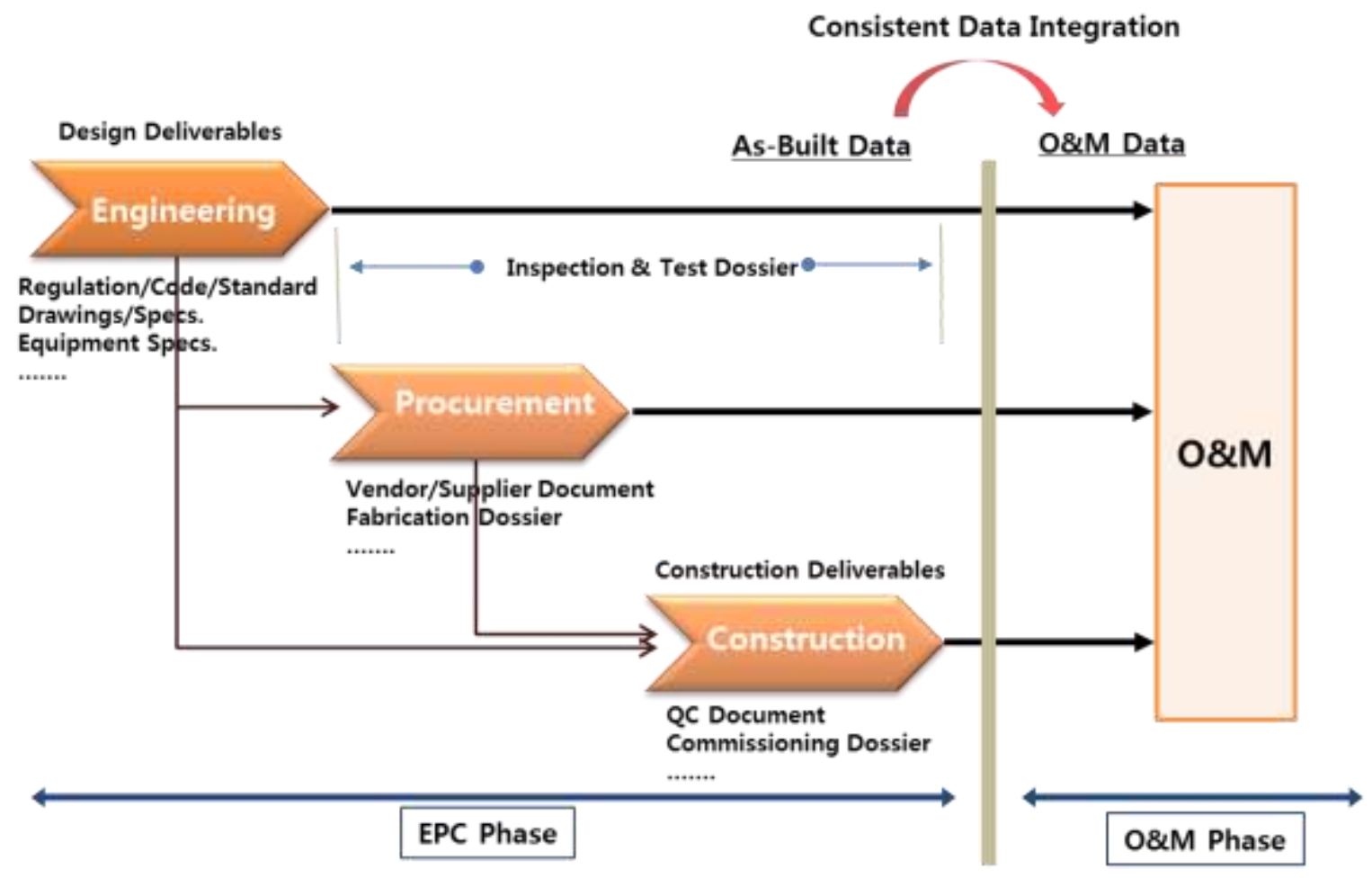

Fig. 1: Interface of Information between EPC phases and O\&M phase 


\subsection{Configuration Management Application Plan}

For systematic configuration management, a configuration management plan should be established and relevant work processes should be composed for their smooth implementation according to the plan.

System Engineering Process for establishing and

maintaining Consistency of a product's performance,

functional and physical attributes with its requirements,

design and operational information throughout its life

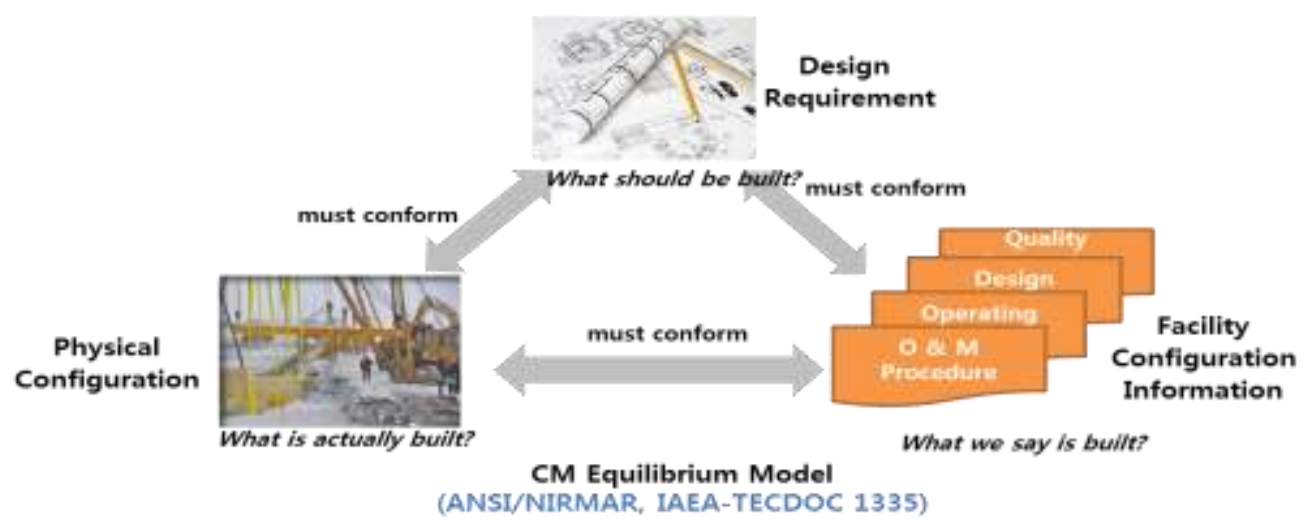

Fig. 2: CM Equilibrium (ANSI/NIRMAR, IAEA-TECDOC 1335)

(1) Required work processes for configuration management

As shown in Table 2, the following configuration management work processes are required for information management of the gas pipeline project.

TABLE II: Required work process for configuration management

\begin{tabular}{|c|c|}
\hline Configuration management work process & Description \\
\hline Program management & $\begin{array}{l}\text { Set priorities of facility configuration management planning and } \\
\text { implementation, set up a direction, and control them }\end{array}$ \\
\hline Design requirements management & $\begin{array}{l}\text { Establish, document, maintain, and use design requirements for the } \\
\text { configuration management targets (structures, facilities, equipment, etc...) }\end{array}$ \\
\hline Information management & $\begin{array}{l}\text { Identify configuration information of facility physical configuration and } \\
\text { design requirement and manage them as information }\end{array}$ \\
\hline Change management & $\begin{array}{l}\text { Analyze modification effects and control the modification process in order } \\
\text { to maintain consistency between design requirements, physical } \\
\text { configuration, and facility configuration information when configuration is } \\
\text { modified }\end{array}$ \\
\hline Evaluation & $\begin{array}{l}\text { Evaluate how efficiently basic relations between design requirements, } \\
\text { physical configuration, and facility configuration information are } \\
\text { established and maintained }\end{array}$ \\
\hline Training & $\begin{array}{l}\text { Guarantee that all who are involved are well informed of the vision, } \\
\text { concept, definition, and procedure of configuration management }\end{array}$ \\
\hline
\end{tabular}

(2) Information required for configuration management

Even though a systematic plan should be established above all for configuration management, actual configuration management work requires considerable effort. Therefore, an adequate computer system should be introduced and a comprehensive IT environment should be created considering the purposes of configuration management of an organization. Since a computer system for configuration management should be able to fittingly provide information for supporting complicated configuration management work, it should fulfill the following information presentation requirements as shown below. 
TABLE III: Basic information required for configuration management

\begin{tabular}{ll}
\hline \hline Category & Required information \\
\hline Requirements information & Guide/Regulation, design standards, and margin \\
Plant information & P\&ID, 3D, specifications, SSC properties, and SSC level categorization \\
Operational information & Facility tag, installation information, maintenance plan, and preventive \\
& maintenance plan \\
Gther information & $\begin{array}{l}\text { Ground \& foundation, failure history, Scope of role/work, and information } \\
\text { for decision-making of configuration changes }\end{array}$ \\
\hline
\end{tabular}

\subsection{O\&M Information Management Framework using Configuration Management}

O\&M of the gas pipeline project has been conducted for decades. Maintenance begins as soon as a project is finished with the completion of the construction stage. The important thing is that data and information transfer is not smooth sometimes because of different main agent modes. To prevent this, the V-model is applied for configuration management as shown below.

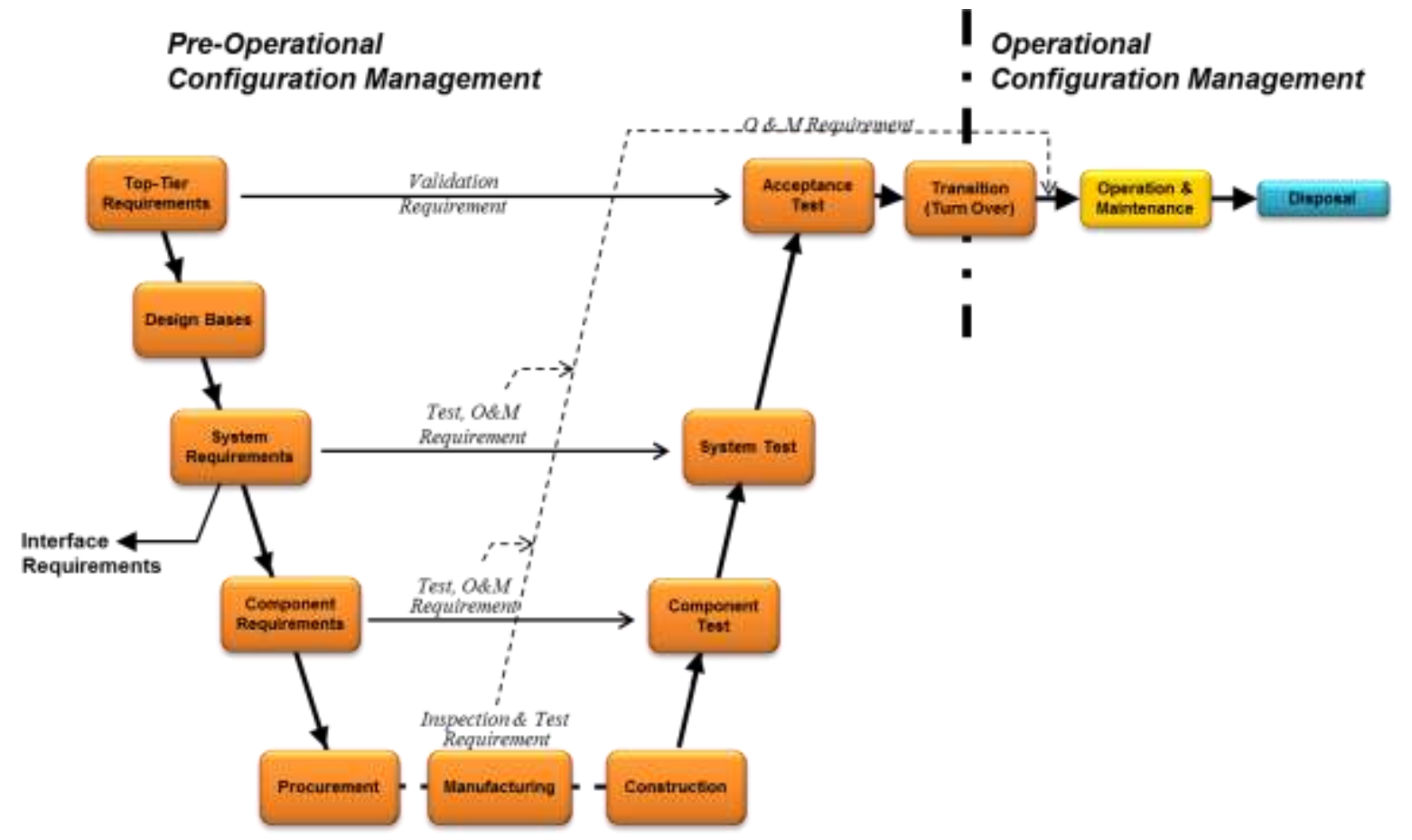

Fig. 3: Configuration Management V-Model

According to the figure above, the requirements of the design stage are sequentially satisfied and managed well if sustainable traceability is secured from the early project stage. The important thing is how to manage changes generated during the project. Therefore, information is repetitively checked and recorded/saved using the configuration management equivalency evaluation process as shown below.

The change management process is vital for the efficient management of the huge amount of data generated during a long-term project. In this study, a configuration management technique is applied for data management of the gas pipeline project and the key is change history management. The figure below shows the change management process. 


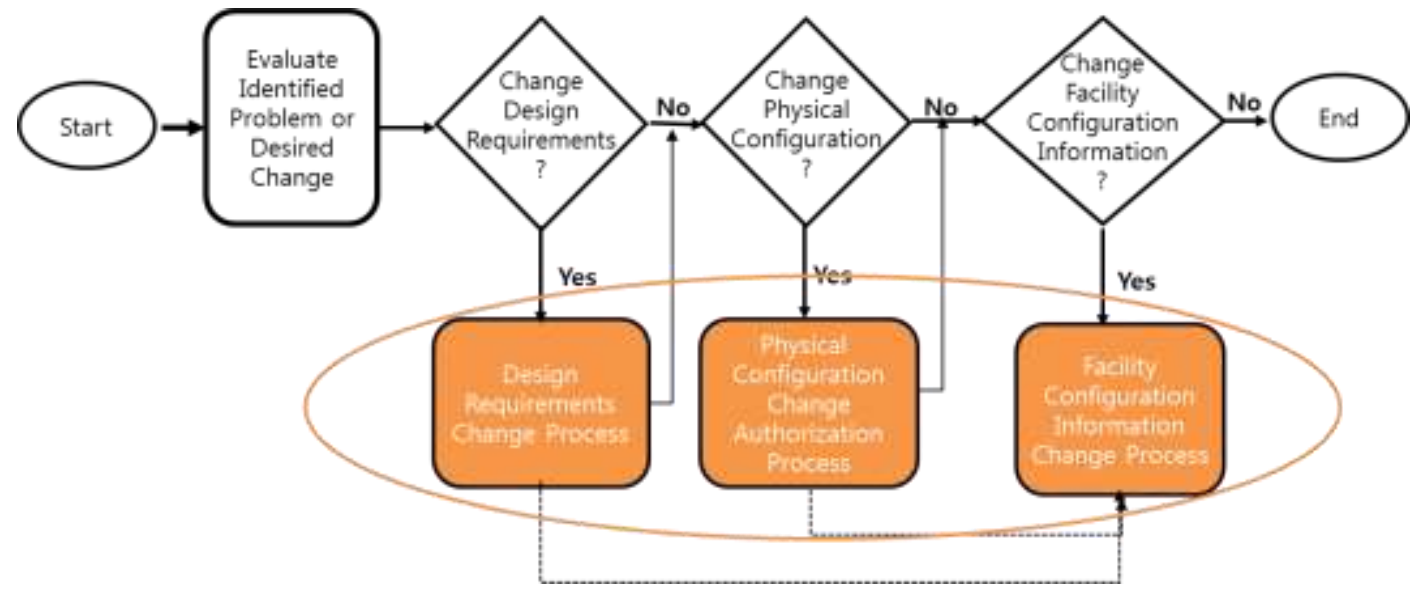

Fig. 4: Configuration Management Equivalency Evaluation Process

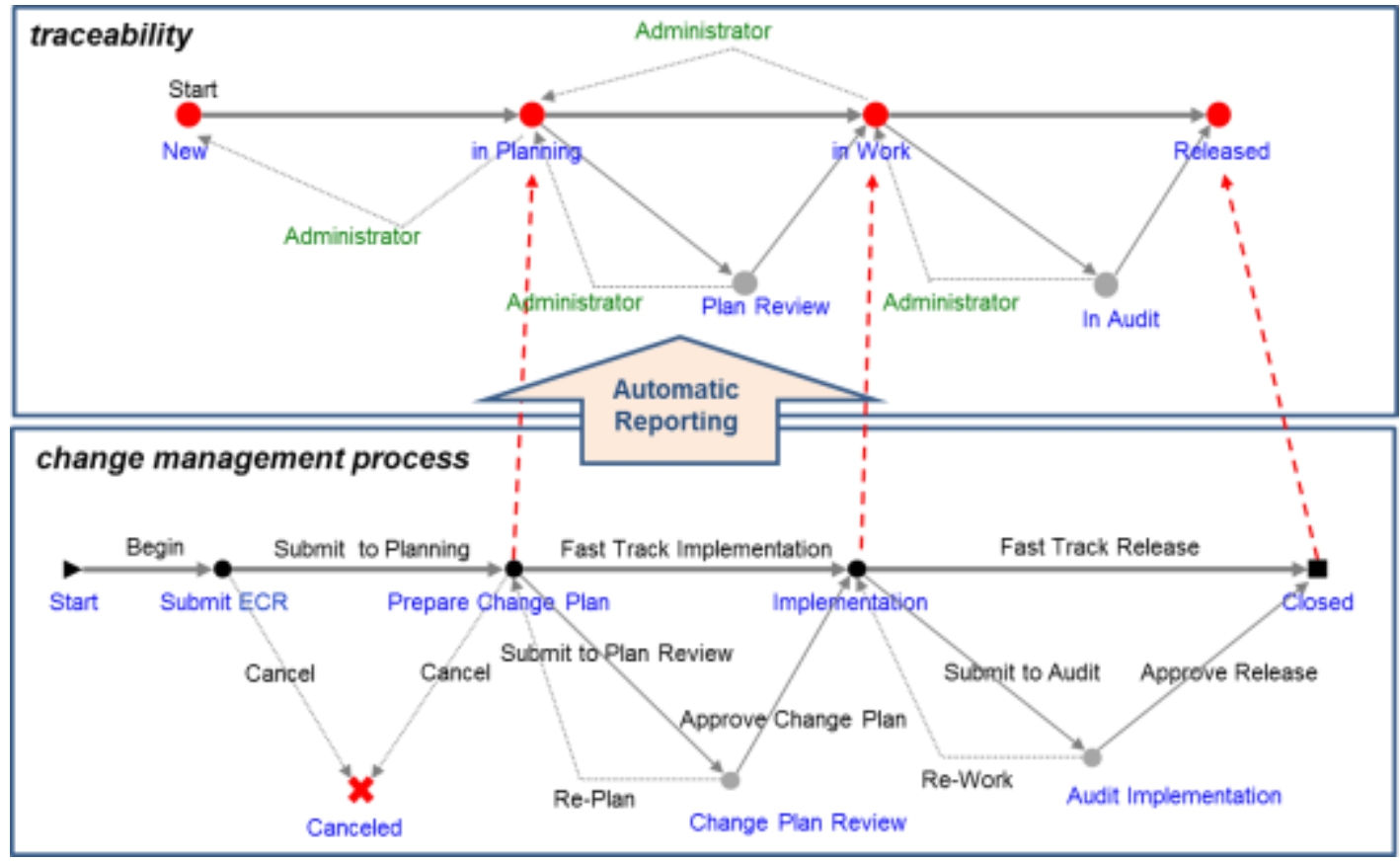

Fig. 5: Traceability \& change management process

\section{Conclusion}

This dissertation is part of the research conducted to develop an efficient data management system for the gas pipeline project in the permafrost areas. In particular, the maintenance stage-centric data management system is an important part of the entire project lifecycle. In this study, the data management technique using configuration management is selected and applied. Configuration management, originally applied for weapons development and space development, is being introduced to nuclear power plant projects. A huge amount of data will be generated during the gas pipeline project and should be converted into and used in various forms for each stakeholder. In that regard, this study is in an early stage and will be conducted again three years from now.

In this study, it was found that the introduction of configuration management techniques is suitable for the development of the O\&M data management framework for pipelines of the permafrost areas. The major performances of this study are as follows: Firstly, the data breakdown structure of the pipeline lifecycle in the permafrost areas was deducted, secondly, the configuration management technique was surveyed and analyzed, and thirdly, a configuration management application plan was proposed. In particular, further studies will be 
conducted about details of data management framework development, focusing on the change history management process.

\section{Acknowledgements}

This research was supported by a grant (13IFIP-B06700801) from the Industrial Facilities \& Infrastructure Research Program funded by the Ministry of Land, Infrastructure and Transport of the Korean government.

\section{References}

[1] C.H.Kim, S.K.Won, J.B.Lee, and C.H.Han, "A Fundamental Study on Data Item occurred in EPC Stage of Pipeline in Extreme Cold Weather." presented at the annual concference of the Korea Institute of Building Construction, May. 2014.

[2] C.H.Kim, S.K.Won, J.B.Lee, and C.H.Han, "A Fundamental Study on Management Plan of Occurrence Data in Accordance with Engineering \& Construction of Pipeline in Frozen Soil Region." presented at the annual concference of the Korea Institute of Building Construction, May. 2014.

[3] C.H.Kim, S.K.Won, J.B.Lee, and C.H.Han, "A Study on the Data Classification in Engineering Stage of Pipeline Project in Extreme Cold Weather." presented at the annual concference of the Korea Institute of Building Construction, Nov. 2014.

[4] Development of Site Investigation and Monitoring System for Extremely Cold Regions. Korea Institute of Civil Engineering and Building Technology, December 2012.

[5] PODS 6.0 - Release 6 Final Ver.(2014.11)

[6] Russian Gas Just Around the Corner, Finding a Way of Using It for Economic and Diplomatic Leverage. JoongAng Ilbo, May 2014.

[7] S.K.Won, C.H.Kim, C.H.Han, and J.B.lee, "Development of O\&M Data Management System for Pipeline Project in Permafrost Area." presented at the ISARC, Oulu, Finland, June 15-18, 2015

[8] S.W.Hong, Y.J.Kim, S.B.Heo, and G.Y.Gong. Development of Effective Methods for Design and Construction of Foundations in Cold Regions (Report on the first project year). Ministry of Science and Technology, pages 40-42, July 1992.

[9] TATA Consultancy Services(TCS), Integrated Pipeline Management Solution

[10] The Value of an Integrated Pipeline Information Management System for OMV Group, PODS EMEA 2013 Presentations

[11] Y.S.Kim, H.S.Hong, and C.H.Hong, "Method of Frozen Ground Assessment and Site Investigation Technology."the Magazine of the Korean Society of Civil Engineers, pp. 26-34. Available : http://www.ksce.or.kr/newsletter/130627/pdf/04.PDF 